\title{
UNA NOTICIA DESCONCERTANTE SOBRE LA INSCRIPCIÓN DE SAN JUAN DE BAÑOS OFRECIDA POR ÁLVAR GÓMEZ DE CASTRO
}

\author{
POR \\ ISABEL VELÁZQUEZ y ROSARIO HERNANDO \\ Universidad Complutense ${ }^{1}$
}

PALABRAS CLAVE: Epigrafía latina. Inscripciones visigodas. Inscripciones fundacionales. Inscripciones funerarias. Humanistas. Transmisión epigráfica. Recesvinto. Álvar Gómez de Castro. Iglesia de San Román de Hornija (Valladolid). Iglesia de San Juan de Baños (Palencia). Siglo vII. Siglo XVI.

KEY WORDS: Latin epigraphy. Visighotic inscriptions. Funerary inscriptions. Foundation stones. Humanists. Epigraphic transmission. Recesvintus. Álvar Gómez de Castro. Church of San Román de Hornija (Valladolid). Church of San Juan de Baños (Palencia). $7^{\text {th }}$ century. 16 ${ }^{\text {th }}$ century.

\section{RESUMEN}

Se realiza la presentación y análisis de unas breves notas inéditas del humanista Álvar Gómez de Castro, conservadas en el manuscrito 7896 de la BN, sobre cinco conocidas inscripciones. Su interés reside en que constituyen las primeras referencias de cada una de ellas y aportan datos útiles para la historia de las piezas. Pero lo más llamativo es que se presenta una inscripción en S. Román de Hornija con idéntico texto al de la inscripción de S. Juan de Baños. En este trabajo se apuntan algunas hipótesis sobre tan descorcentante y quizás errónea noticia.

\section{SUMMARY}

The paper presents and analyses brief unpublished notes by the humanist Alvar Gómez de Castro, conserved in MS number 7896 in the Biblioteca Nacional, regarding five known inscriptions. Their interest lies in the fact that they are the first references to each one and provide useful data on the history of the pieces. But the most striking is the presentation of an inscription in S. Román de Hornija, the text of which is identical to the inscription of S. Juan de Baños. The paper presents hypotheses on this puzzling and perhaps erroneous fact.

\section{EL DEBATE SOBRE LA CRONOLOGÍA DE LA IGLESIA DE SAN JUAN DE BAÑOS}

Ya desde hace unos años se ha establecido un debate, especialmente entre arqueólogos, sobre la

1 Este trabajo está adscrito a los proyectos de investigación CAM 06/0079/1998 y TEL 1999-395. Agradecemos muy sinceramente las valiosísimas observaciones que nos ha hecho el Dr. Luis Caballero para la elaboración del trabajo. definición del arte de época visigoda a partir de nuevos estudios y análisis de los monumentos arquitectónicos y obras escultóricas considerados tradicionalmente como característicos del siglo vII. La hipótesis revisionista que propone retrasar la cronología de iglesias como San Juan de Baños, San Pedro de la Nave, Santa Lucía del Trampal y un significativo número más de iglesias, a época altomedieval y/o mozárabe ${ }^{2}$, principalmente sostenida por Caballero (Caballero 1994; Caballero y Feijoo 1998; Caballero y Sáez Lara 1999) ${ }^{3}$, tiene la ventaja -con independencia de su confirmación, matización, o posibles modificaciones - de haber sometido a un nuevo estudio en profundidad unas teorías sobre el arte de esta época consensuadas de forma tradicional pero a veces con contradicciones, puntos oscuros y, sobre todo, basadas en escasos elementos de cronología cierta, pero que han servido para definir y caracterizar todo un período (Caballero 1994 : 325-326).

En este contexto, la iglesia de San Juan de Baños, en Baños de Cerrato (Palencia), siempre ha sido considerada como la iglesia paradigmática, a partir de la cual se han estudiado los modelos arquitectónicos de época visigoda. Aunque desde las primeras publicaciones se han detectado problemas de interpretación, su visigotismo se ha presentado, hasta ahora, como incuestionable debido a la existencia de la inscripción fundacional de la misma, fechada en época de Recesvinto ${ }^{4}$. Pero dicho visigotismo ha sido puesto en duda por Caballero y Feijoo (1998) en un exhaustivo trabajo de análisis arqueológico, con estudio de las planimetrías y ordenación estratigráfica de los restos del edificio primitivo. Un trabajo, densísimo y cuidadoso, donde se han recogido todas las noticias sobre la iglesia, las reestruc-

2 Sobre el alcance del término mozárabe, véase el estudio preliminar de I. Bango en la reedición de las Iglesias Mozárabes de Gómez Moreno (Gómez Moreno 1919 [1998] : XIII-XXV).

${ }^{3}$ Nos limitamos a dar una bibliografía somera de este autor, reveladora de su postura.

${ }^{4}$ Sobre la cuestión de la fecha volveremos más adelante. 
turaciones que sufrió y reconstrucciones tanto en época antigua, como posteriores. Todo apunta a pensar que la construcción de la iglesia es de época posterior, aunque reutiliza materiales de decoración que sí parecen de época visigoda.

Caballero y Feijoo establecen así tres grupos de decoración que califican del siguiente modo:

$1 .^{\circ}$ «Decoración reutilizada de tipología visigoda consensuada». A la que «hipotéticamente» podría añadirse la inscripción fechada a mediados del siglo VII «que, de ser así, procedería de otro edificio anterior».

2. «Decoración reutilizada de tipología visigoda discutida, pues podría haberse efectuado por un taller de raíz omeya».

3. Decoración «efectuada para el edificio actual, retallando piezas del grupo anterior o tallando elementos ex novo en un taller con influencias asturianas y otras evolucionadas de los anteriores».

De la lectura atenta de este trabajo, se obtiene la impresión de que la inscripción fundacional es el principal escollo para resolver el problema de datación de la iglesia y de adscripción de la misma a un contexto cultural determinado, en la medida en que la aceptación o no de que su actual ubicación es la primigenia, así como la aceptación de su autenticidad, condiciona inevitablemente el planteamiento general del estudio. A lo largo del mismo, los autores apuntan la hipótesis de que la inscripción procediese de otro edificio anterior, que sería de época visigoda, y fuese aquí reutilizada (grupo $1 .^{\circ}$ de decoración).

No es intención de quienes firmamos este trabajo -ni somos quiénes para hacerlo-, definir nuestra postura ante el estudio de la iglesia, ni, aún menos, entrar en el debate general sobre el arte visigodo; pero sí pretendemos ofrecer un dato - desde el ámbito del estudio de las fuentes documentales y epigráficas - que, sin duda, resulta desconcertante y extemporáneo a toda la discusión, pero que creemos debe tenerse en cuenta y precisamente porque, como se ha expuesto, subyace una problemática no resuelta aún en torno a la famosa inscripción. De hecho Caballero y Feijoo (1998 : 237), en las conclusiones de su estudio, señalan que «si se acepta que la inscripción está reutilizada, se abre una explicación insospechada para este edificio y para la intención que pudo tener quien lo erigiese». Sugieren, incluso, retomando las ideas de los Grabar (1954: 185-7; id. 1965: 869-70; 875-7; id. 1981: 62-3), que pudo deberse a la actuación de príncipes altomedievales que adoptaron linajes de los monarcas del pasado, para vincular sus orígenes a personajes ilustres (Sánchez Albornoz 1980: 362).
Ese dato al que nos hemos referido no es otro que la mención de la existencia de una inscripción con el texto de la de San Juan de Baños en la iglesia de San Román de Hornija en Valladolid, debida al humanista Álvar Gómez de Castro.

Los datos que manejamos $-\mathrm{y}$ las conjeturas o hipótesis que apuntamos- no tienen otro propósito, pues, que ofrecerlos a los especialistas en la arquitectura y arte visigodos y medievales para que analicen en qué medida deben ser tenidos en cuenta.

Sin embargo, con independencia de este propósito, consideramos que presentar las noticias epigráficas que proporciona Gómez de Castro sobre algunos epígrafes, aunque todos ellos bien conocidos, puede resultar interesante al lector, por cuanto que son las primeras referencias de cada una de ellas y ofrecen aspectos peculiares.

\section{LOS MANUSCRITOS DE ÁLVAR GÓMEZ DE CASTRO}

Este humanista (ca. 1515-1580), natural de Santa Olalla (Toledo), adquirió su formación universitaria en Alcalá de Henares, donde llegó a desempeñar las Cátedras de Menores y Mayores de Griego, manteniéndose en ésta última hasta 1547-1548. Además de maestros como Juan Ramírez, sucesor de Nebrija y rector de la Universidad, o Francisco de Cedillo, catedrático de Griego, tuvo entre sus amigos a Luis de la Cadena, Juan Hurtado de Mendoza, Juan de Vergara y a Ambrosio de Morales, que será el primero de los autores que registre la existencia de la inscripción fundacional de San Juan en Baños de Cerrato, cuestión esta sobre la que volveremos.

En 1548 o 1549 abandona Alcalá, por motivos no suficientemente esclarecidos, para ocupar la capellanía de Blacos (Segovia) ${ }^{5}$ hasta 1552 en que se instala definitivamente en Toledo, donde imparte clases de griego en el Colegio-Universidad de Santa Catalina, compaginando su actividad docente con sus trabajos de investigación y estudio, la preparación de certámenes literarios y la composición de versos latinos.

A partir de 1560 su actividad sufrió cambios sustanciales; las investigaciones de carácter puntual,

${ }^{5}$ La información sobre este periodo se debe casi exclusivamente a las noticias conservadas en la correspondencia epistolar mantenida con Pedro de la Rúa, el célebre crítico de las obras de Fray Antonio de Guevara, que por entonces era catedrático de gramática en Soria. Las cartas autógrafas se encuentran recopiladas en el ms. 8624 de la Biblioteca Nacional, así como una copia de las mismas realizada en el siglo XVIII (ms. 13008). 
erudito y, en cierto modo, asistemáticas, dejaron paso a los grandes proyectos ${ }^{6}$; publicó una obra sobre el recibimiento de Isabel de Valois en Toledo, emprendió trabajos de traducción de las cartas griegas de Marco Bruto y del Enquiridion de Epicteto; escribió una monografía sobre la institución de las vestales usando fuentes latinas e intentó escribir, al parecer, una tragedia basada en el canto séptimo de la Ilíada, aunque, si llegó a hacerla, no se ha conservado. A esta etapa pertenece también su gran obra sobre la vida del Cardenal Cisneros, sin duda la más conocida y la que le ha otorgado más fama ${ }^{7}$.

Los últimos años de su vida los empleó, además de en la lectura y anotación de las obras de San Ambrosio, en dos proyectos de gran magnitud: colaboró en la creación de la Biblioteca de El Escorial ${ }^{8}$ e inició los trabajos de recogida y consulta de códices para la edición de las Etimologías de Isidoro de Sevilla, ayudado por humanistas como Antonio Agustín, Pedro Chacón y Antonio de Covarrubias. Esta actividad suscitó en él un gran interés por los códices antiguos relativos a los concilios de época visigoda. En ella se hallaba inmerso cuando murió el 16 de septiembre de 1580 .

Estos apuntes biográficos, mínimamente referidos aquí ${ }^{9}$, sirven para recordar ahora que Álvar Gómez de Castro es uno de los humanistas más sólidos y que gozó de un reconocido prestigio tanto en los ambientes culturales de su época ${ }^{10}$ como en si-

${ }^{6}$ Hasta ese momento sólo había publicado dos libros: la recopilación de poesía latina Publica laetitia qua D. Joannes Martinus Siliceus Archiepiscopus Toletanus Compluti susceptus est (Compluti, apud Ioanes Brocarius, 1546) y los Edyllia aliquot sive poematia (Lugduni, apud Gasparum Treschell, 1558).

7 Redactada en un periodo asombrosamente breve (según parece deducirse de los textos, empleó menos de cuatro meses), De rebus gestis a Francisco Ximenio, Cisnerio, Archiepiscopo Toletano, libri octo, Compluti, apud Andream Angulo, 1569, cf. López de Toro 1958 y, especialmente, Alvar Ezquerra 1980; id. 1982; id. 1985, y Oroz Reta 1984.

8 Aunque manifiesta sus temores en cuanto al afán de Felipe II por conseguir libros para el Escorial «porque al fin lungae sunt regium manus y alcanzan donde quieren» $\mathrm{y}$, no obstante, parece que, finalmente, consiguió que la biblioteca de su protector, el cardenal Francisco de Mendoza y Bobadilla, fuese adquirida por el cabildo de Toledo, por lo que, en la actualidad, una buena parte de los mismos están depositados en la Biblioteca Nacional, cf. L. Gil 1997: 657.

9 Hemos seguido fundamentalmente la exposición de $\mathrm{Al}$ var Ezquerra 1980. Véase también Gil 1997: 308, passim.

${ }_{10} \mathrm{Y}$ eclesiásticos; recuérdese que el Santo Oficio le pidió consejo para la elaboración del Indice de Quiroga, y que Gómez de Castro, con una actitud lo más abierta posible en su momento, redujo al mínimo los autores clásicos que deberían figurar en él, como escribió en su famoso Parecer (ms. 13009 de la Biblioteca Nacional) y que Sánz Serrano publicó a comienzos de siglo como de Zurita, a partir de una copia distinta. Sobre esta cuestión, véase nuevamente Gil 1997: 484. glos posteriores, por lo que, en principio, nada hace sospechar de la veracidad de sus informaciones. Igualmente sirven para establecer la relación personal con Ambrosio de Morales que, creemos, no debe ser ajena a la noticia proporcionada sobre la inscripción que nos ocupa, aunque no existan -o no hayamos localizado- elementos concretos que puedan atestiguarlo.

En la Biblioteca Nacional existe una colección miscelánea de cuatro manuscritos, mss. 7896, 7897 , 8624 y 8625 , compuesta en su mayor parte por documentos autógrafos, que Álvar Gómez de Castro escribió durante su etapa de residencia en Toledo y con el conocimiento de los fondos bibliográficos de la Biblioteca Primada (Alvar Ezquerra 1980: 154). Como anota Sánchez Cantón (1919: 161): «después de traducir a Epícteto extractaba al canciller de Ayala, copiaba a Horacio y en la siguiente página recordaba estrofas del arcipreste de Hita, y con la misma tinta con que dirigía a Juan de Vergara una ciceroniana epístola, anotaba la suscripción de un manuscrito del siglo $\mathrm{x}$; confusión de asuntos que juzgarían sacrílega un Budeo o un Valla». Efectivamente, si hay un rasgo que defina el carácter de estos manuscritos es el de su extremado desorden; cada volumen de la serie no es más que una acumulación de papeles, en muchos casos borradores en los que se hallan los gérmenes de lo que luego serán sus obras impresas. Este desorden responde, en última instancia, a la aplicación de un método de estudio que Gómez de Castro debió de empezar a emplear en su etapa alcalaína y que había sido importado y difundido por los profesores bizantinos llegados a Italia en el siglo $x v$ y que fue introducido en España por Luis Vives, quien lo descubrió en los Países Bajos. El objetivo de tal método no era otro que aprender a escribir en latín basándose en la imitación de los antiguos (especialmente Cicerón); el estudio había de centrarse en la lectura directa de los textos de los autores clásicos, teniendo a mano un cuaderno en el que ir anotando, ordenados por secciones temáticas, vocabulario, expresiones idiomáticas, sentencias, proverbios, pasajes de especial dificultad, etc., «así, cuando un estudioso había recorrido, cuaderno en mano, los autores latinos y griegos (éstos, en muchas ocasiones, acompañando su lectura de ejercicios de traducción al latín), se encontraba en posesión de un caudal léxico, de construcciones y frases hechas, de referencias eruditas, doctrinales y de ejemplos sobre el cual podía construir, como un mosaico, sus propios textos» (A. Fontán 1972: 196).

El carácter misceláneo y, a veces, de apariencia un tanto caótica de los escritos derivados de este método, unido al afán por anotar cuanto se conside- 
ra de interés, sea de la temática que sea, parece inevitable. Con todo, y precisamente por ello, es incuestionable el valor de las anotaciones de Gómez de Castro y, pese a su desorden - que, como apunta A. Alvar (1980: 155), hace más meritoria la obtención de datos aprovechables - constituyen no sólo un testimonio elocuente del Humanismo español, sino también una fuente de información, rica y variada, sobre aspectos lingüísticos, literarios e históricos, especialmente de época medieval. No es extraño que Dámaso Alonso (1970: 64, nota 4) los denominara «tesoro de papeles varios».

De los manuscritos referidos, el ms. 7896, que consta de 622 folios $(226 \times 155 \mathrm{~mm}$, papel $)$, contiene, según cabe esperar, una variada serie de elementos, de cuya diversidad puede dar una idea la estructuración que del mismo ha hecho Antonio Alvar (1980: 2333-269) en cuarenta y nueve epígrafes. Contiene este manuscrito epigramas y otras composiciones métricas latinas, frases en griego con traducción al latín, comentarios a autores y textos griegos y latinos diversos; comentarios a las Sagradas Escrituras; cartas latinas a Honorato Juan, Ambrosio de Morales, Pedro de Soto, al Rector de la Universidad, etc.; discursos en latín; comentarios a diversos pasajes de la literatura clásica, explicando símbolos; explicaciones de términos latinos; epitafios latinos diversos a humanistas, a Juana reina de España; inscripciones para diversos lugares; y un largo etcétera ${ }^{11}$.

De la clasificación de Alvar mencionada, el grupo $n .^{\circ} 26$ está constituido por los folios 354-374. En ellos se contienen versos en castellano de distintas manos; ensayo de inscripciones para monumentos públicos; dísticos latinos; inscripciones de época visigoda de diversas localidades; poemas en castellano (de Gómez de Castro a Francisco Soto y viceversa); y breves composiciones en castellano y latín.

\section{APUNTES EPIGRÁFICOS CONTENIDOS EN EL MS. 7896 DE LA BIBLIOTECA NACIONAL}

Los únicos apuntes epigráficos sobre inscripciones antiguas contenidos en este manuscrito, se reducen a los presentes en este apartado, ya que los demás son composiciones personales de él o de su época. Ocupan los folios 365, recto y verso, y 366 recto. Se trata de una nota autógrafa fechada en 1565 , la más moderna de las que conforman la colección miscelánea.

\footnotetext{
11 Remitimos a Alvar Ezquerra 1980: 236-269, para una descripción in extenso del contenido, que aquí resultaría prolijo intentar reproducir, aun resumiéndola.
}

En esta nota se da cuenta de la existencia de cinco inscripciones latinas de época visigoda procedentes de las localidades de Sevilla, Cabra (Córdoba), Lebrija (Sevilla) y San Román de Hornija (Valladolid).

En cada uno de los casos se anotan, simplemente, el lugar de procedencia de cada una de las piezas y, a continuación, su texto. Como podrá observarse, los criterios de Gómez de Castro no son propiamente epigráficos, sino que parece moverle un interés meramente curioso y, en todo caso, filológico. Desarrolla las abreviaturas, salvo alguna excepción, como la de kal(endas), regulariza grafías y no respeta las líneas de escritura, salvo en el caso de la inscripción última - la que contiene el texto de San Juan de Baños-, posiblemente por tratarse de una composición en verso.

Dada la cronología de las menciones, 1565, que él mismo hace explícita al hablar de las dos primeras piezas, su testimonio se convierte en el primero de los conservados para estas inscripciones concretas. A este respecto se debe llamar la atención sobre el hecho de que estas menciones epigráficas pasaron desapercibidas a los autores coetáneos e inmediatamente posteriores y tampoco han sido tenidas en cuenta en la elaboración de los corpora de referencia más habituales. Para las inscripciones que recoge Gómez de Castro el primer dato mencionado por todos los estudiosos es sistemáticamente Ambrosio de Morales, su Coronica General de España, continuación de la de Florián de Ocampo, y que se editó a partir de $1574{ }^{12}$, de manera que la mención de nuestro autor es la primera. Esto no sólo es llamativo, sino que debe ponerse en relación con el estado en que se presenta cada inscripción con respecto a las lecturas tanto de Morales como de otros autores. Creemos que no es por casualidad que estas inscripciones presenten peculiaridades sobre su transmisión que, sin duda, deben ser comparadas y examinadas a la luz de estas breves noticias de Gómez de Castro, especialmente si tenemos en cuenta, como se dijo anteriormente, que mantuvo amistad y correspondencia con Ambrosio de Morales, aunque en la que hemos podido

12 Salvo error nuestro, no hemos conseguido localizar la referencia que sobre la inscripción de Lebrija, de las aquí recogidas (ICERV 131), hay, según Recio Veganzones (1979: 58), en la parte de la Crónica General de España realizada por Florián de Ocampo. Es decir, los cinco primeros libros, cuya primera edición se efectuó en Zamora el 15 de diciembre de 1543 en la imprenta de Juan Picardo; siendo reeditados resumidos sólo los 4 primeros en 1545 y luego completos en Medina del Campo en 1553; que después ya serían reeditados en 1578 con la continuación de Ambrosio de Morales (información tomada del prólogo de la edición de 1791, p. 59). 
localizar hasta el momento no hemos encontrado mención explícita a inscripciones ${ }^{13}$. Creemos, no obstante, que pudo existir un intercambio de informaciones o fuentes comunes de obtención de datos -indudable en relación con las de Sevilla-; aunque eso no quiere decir necesariamente que, a pesar de ser anterior el testimonio de Gómez de Castro a la edición de Morales, la dependencia sea de éste con respecto al primero. Sin embargo, es, precisamente, el dato relativo a la inscripción de San Juan de Baños, y algunos otros, el que abre el interrogante sobre esta posible relación, como analizaremos en su lugar.

Las noticias sobre inscripciones son las siguientes:

\section{1-2: Sevilla:}

«Este año de 1565 cauando en Seuilla cabe San Bernardo se hallaron dos tumbas de muy lindo marmol. Dentro auia huessos y sendos vasos de vidrio llenos de cierto liquor, que no se entendio que era, mas estaua muy conservado.

En la una tumba dize:

Paula clarisima foemina famula

Christi vixit annos XXIIII menses

duo. Recessit in pace die XVI. kal. Februarias. Era DLXXXII.

En la otra tumba dize:

Ceruella clarissima foemina famu
la Christi vixit annos plus minus
annos XXXV. Recessit in pace
die III Kal. Februarias Era DC.»

En nota marginal, junto a la primera inscripción añade «hic ann 9 eadii Gotho Regis Tyra». Y en otra nota marginal, junto a la segunda: «ad huc Teu» ${ }^{14}$.

${ }^{13}$ No exenta, en cambio, de intereses históricos, como la carta, ya estudiada por Gigas (1909), de Morales sobre la localización de Mentesa fechada en 1570.

14 Seguramente se trata de una referencia a los años de reinado marcados en las fechas de las inscripciones, pero parece tratarse de un error, y estar intercambiadas, ya que la primera, del año 544, corresponde al gobierno de Teudis en su año décimo tercero (o décimo cuarto), pues fue rey del 531-548, a quien parece referirse la nota marginal de la segunda inscripción; en cambio, la fecha de ésta segunda corresponde a Atanagildo (rey del 555 al 567), ya que es el año $562 \mathrm{y}$, por tanto, su octavo año (no noveno); sin embargo la abreviación Tyra de esta nota marginal primera parece hacer referencia al año de reinado de un gothorum regis tyranni y debe recordarse que Atanagildo usurpó el poder, mediante una guerra civil y con ayuda bizantina, a Agila.
El texto de ambos epígrafes se conoce sólo gracias a las copias realizadas en época renacentista, constituyendo la que aquí presentamos la de mayor antigüedad, pues se fecha en el mismo año del hallazgo de las piezas.

Estos dos epígrafes se registran, igualmente, en un manuscrito anónimo de la Biblioteca Nacional, ms. 6149/38, fol. 114r-v, que fue estudiado por J. Gil (1971: 284), quien señala que se trata de una de las copias más fieles que poseemos al respecto de la lectura de estos monumentos. Además de la fidelidad de las lecturas, este manuscrito ofrece diversos datos de interés al respecto de las características físicas de ambas piezas.

La primera lápida corresponde a ICERV 110 (= IHC 68, CILA 2, 150). Gómez de Castro no registra más características de la pieza que la relativa al material del soporte -mármol-, aunque nada dice sobre sus medidas, decoración, características de letras o tipo de signos de interpunción, aunque la alusión que hace al hallazgo pone de manifiesto que la información de que dispuso fue muy similar a la de Ambrosio de Morales ${ }^{15}$. La lectura no presenta variantes con respecto a la transmitida en los repertorios de referencia, aunque presenta las abreviaturas desarrolladas con excepción de la relativa a $\mathrm{ka}$ lendas, de la misma forma que hará Morales; pero, a diferencia de éste, ofrece la lectura duo en lugar de duos, como la da también el citado manuscrito 6149. Tampoco la distribución de líneas coincide con la de las fuentes manuscritas o impresas recogidas en los corpora de referencia; sin embargo, a este respecto hay que advertir que, como se indica tanto en ICERV como en $I H C$, para esta inscripción y para la siguiente, hay dudas en las fuentes sobre la división de renglones ${ }^{16}$.

15 Es importante destacar las dos fases detectables en el comentario de Ambrosio de Morales, ya que señala que hace algunos años aparecieron (frente a Gómez de Castro que dice exactamente «en este año de 1565») y que él las ha visto (quizá bastante después). En el libro XI, cap. 53 (Morales 1791: 491-492) dice: «De tiempos deste Rey (sc. Teudis) en una de dos sepulturas que pocos años se hallaron debajo tierra fuera de Sevilla, en aquel arrabal que está á la Iglesia de San Bernardo, en la qual, por ser las mugeres católicas y muy ilustres, las metiéron. Yo las he visto y son grandes arcas de marmol, con sus cubiertas de otro marmol algo diferente, todo liso, sin ninguna pulideza. En cada una se halló una redoma de vidrio, que parece tuvieron algun liquor; mas ya estaba consumido del tiempo» (Gómez de Castro señala, en cambio, que está en buen estado). Como se dijo ya en el texto, creemos que la relación entre ambos autores es notable.

16 Podría pensarse en la distribución que ofrece Ambrosio de Morales que insiste en que ha visto las piezas, aunque es sabido que no ofrece siempre la distribución de líneas correcta. 
Por lo que respecta a la segunda inscripción, se trata de ICERV 111 (= IHC 66, CILA 2, 143). Como en el caso precedente, su lectura resuelve todas las abreviaturas, salvo la referida a kalendas $\mathrm{y}$, como se ha advertido, presenta también una distribución de líneas distinta. Sí presenta, en cambio, una variante de lectura y es la intercalación entre vixit y plus minus de annos, de manera que plantea la misma y extraña repetición que se registra en el referido manuscrito 6149: vixit annos plus minus annos.

A tenor de las coincidencias observables entre el manuscrito 6149 y la nota de Gómez de Castro, no cabe duda de que existe una relación entre ellos; tal vez, incluso, una vinculación directa, aunque el ms. 6149 anota los textos a renglón corrido y es una copia ${ }^{17}$; pero puede afirmarse que parten de una fuente común, coetánea a Gómez de Castro, si es que aquél no depende de éste directamente.

\section{Cabra (Córdoba):}

«En Cabra en la iglesia de San Juan esta un marmol quadrado escrito por los quatro lados con estas letras q. tienen muchas abreviaturas.

\section{Ara sancta domini nostri Iesuchristi Consecrata est basilica haec sanctae Mariae II Kal. Iunias. Era DCXXVIII. Dedicauit hanc aedem Deo Maximo Sacram Bacauda Eps.cps. Fun dauit eam altissimus per Eulali am et filium ejus Paulum mona chum».}

En nota marginal, a propósito de líneas 4-5: «puede dezir Diuae Mariae Sacram».

Corresponde a ICERV 308 (= IHC 100, CIL II ${ }^{2 /}$ $5,299)$. Se trata de un ara moldurada, conservada en la sacristía de la iglesia citada y de la que hay unos

17 Ms. 6149/38 [Papeles histórico-políticos. 38. Suma de una carta en pergamino de la consagración de la iglesia de San Juan de Madrid, era MCXCII, inscripciones de sepulcros hallados en Sevilla, exposición de nueve alfabetos]. s. XVI-XVII, 309 fols., papel, 315 x $320 \mathrm{~mm}$. Copia de documentos recogidos por Pedro de Mármol.

18 Agradecemos sinceramente al Dr. Luis Balmaseda que nos haya enseñado los vaciados y el archivo de la citada colección. En el momento de cerrar este artículo no hemos podido localizar el correspondiente a la cara c (según la edición del CIL II²/5, 299, véase nota 21 ) ni las fichas de inventario; sin embargo, es curioso anotar que en el archivo de Góngora se reproducen los textos de tres de las caras, como de dos vaciados en escayola en el Museo Arqueológico Nacional, procedentes de la colección Góngora ${ }^{18}$. La pieza apareció en una iglesia de Zambra (así en $I H C$ ), o bien de el Campillo, en Cabra (así en $\left.C I L \mathrm{II}^{2}\right)$-en cualquier caso en el antiguo territorio de Cisimbrium -, en torno al año 1550 y trasladada a la iglesia de San Juan de Cabra, en la que hizo de soporte de pila de agua bendita.

Como en los casos anteriores, el testimonio de Gómez de Castro resulta ser más antiguo que las demás referencias recogidas en los corpora citados ${ }^{19}$. Las variantes de lectura estriban en el desarrollo erróneo, por parte del autor, de la abreviatura $d m s$, ante la cual él mismo duda y ofrece al margen una segunda posibilidad (según se ha transcrito, frente a la correcta de $d(o) m($ inu $) s$ ), y en la lectura de la era anotando DCXXVIII, donde se ve claro que el autor no ha sabido interpretar un nexo LXL, con una forma característica de inscripciones de esta época, proponiendo XX, frente a la lectura correcta $D C L X L V I I I$, es decir, 698 de la era, correspondiente al $660^{20}$.

Merece la pena destacar que todos los editores de esta pieza aceptan unánimemente las restituciones propuestas por Pérez Bayer (1782-1785) y que coinciden con la lectura que presenta aquí Gómez de Castro y que da también Morales ${ }^{21}$, salvo en lo relativo a la distribución de líneas.

inscripciones distintas, faltando la relativa a la cara c, que es, precisamente, la que peor se conserva.

19 Morales el primero, ya que Fernández Franco es citado apud Díaz Rivas ms. saec. XVII: Varie iscrizioni et monumenti quali si trovano nella Spagna o in autori spagnoli, con osservazioni sopra di essi in lingua spagnola (Bibl. Estense Universitaria, Módena, sign.: ms. estero $111=$ a.G.7.2 ).

20 A pesar de la infrecuente secuencia LXL, ésta es la fecha que debe admitirse, dada la cronología del obispo Bacauda. Con todo, el error de lectura es comprensible, dada la forma de las letras.

${ }^{21}$ Morales hace la siguiente observación (Lib. XII, cap. 28): «Yo pondré lo que yo leí en la piedra, y han leido otros hombres doctos y diligentes en todo género de antigüedad» ( a quiénes se refiere?). Merece la pena comentar en este punto que Hübner en $I H C 100$ ofrece la lectura a partir de los vaciados de escayola citados (véase nota 18): «descripsi et ectypa sumpsi; unde de lectione constat praeter tituli 2 , cuius periit magna superficiei pars» (es decir, la cara c). Aunque cita a Morales y otros autores a partir de él, sigue para la restitución de la citada cara la lección de Pérez Bayer: «Bayer viaje ms. f. 123 et inde in ed. Marianae Valentinae 2 [1785] p. 312, quem sequor in iis, quae perierunt». Del mismo modo Vives en ICERV 308: «los suplementos de esta cara, de Pérez Bayer, quien debió ver la piedra en mejor estado, merecen absoluta fe». No obstante, la nueva edición del CIL $\mathrm{II}^{2} / 5,299$ presenta ahora una lectura completa de la inscripción, sin restituciones, con una distribución de partes distinta. La cara aludida ofrece la lectura: [(crux)] /Fundauit eam / Altissimus / per Eulaliam / et filium eius / Paulum $\operatorname{monac}(h) u(m)$ 


\section{Lebrija (Sevilla):}

«En Lebrixa encima de la puerta de la iglesia mayor. En una gran piedra.

\section{Alexandria Clarissima foemina ui xit annos plus minus $X X V$. recessit in pace decimo Kal. Ianuarias Era DIII. \\ Probus filius vixit annos duos. men.»}

Se trata de ICERV 131 (= IHC 84, CILA 4, 1009). Es también la primera noticia de la pieza. Es una lastra de mármol que efectivamente se encuentra sobre la clave de la puerta del Sol de la iglesia parroquial de Lebrija y está decorada con un crismón flanqueado por dos palomas.

La lectura de Gómez de Castro no se ajusta a la distribución real de las líneas y no registra la última línea de escritura. Sin embargo, hay que hacer notar en este punto que las fuentes primeras que documentan esta inscripción, recogidas por Hübner (IHC 84) y Vives (ICERV 131), ofrecen la misma era que Gómez de Castro, DIII, hasta Ponz (1794) ${ }^{22}$ y Murator (1824: 7, ex schedis suis, quizá del Cataneo, según Hübner), que ya dan DXXXIII. También señala Hübner que todos los autores, excepto Pérez Bayer, cuyo facsímil presenta, dan la lectura del nombre Alexandra, frente a Alexa(n)dria que es lo que se lee en la pieza ${ }^{23}$ y que, como puede observarse ofrece Gómez de Castro, aunque con la abreviatura desarrollada como acostumbra. En cambio, todos ofrecen la lectura femina, como Gómez de Castro, si bien éste regularizándola en foemina, excepto Pérez Bayer, de nuevo, que presenta femena, según se ve en el facsímil.

Gómez de Castro omite la última línea del texto, que continúa con la última sílaba de men/ses, y presenta men., como si hubiera interpunción y estuviese abreviada, cuando en esa última línea se lee: ses dece $(m)$ recess [it in pace]. No deja de resultar curioso que Ambrosio de Morales finalice la inscripción con men. I, Caro como mensem unum y el propio Murator menses... ${ }^{24}$, y que, según refleja el facsímil, en esta última línea sólo se lean parcialmente las letras conservadas.

Por último, Gómez de Castro, al igual que hará

${ }^{22}$ Libro XVIII, carta $4^{\mathrm{a}}, \mathrm{n}^{\mathrm{o}} 26$. Corresponde al volumen último publicado póstumamente en 1794 y concluido por Joseph Ponz, sobrino del autor.

${ }_{23}$ Ponz, en realidad, da Alexanda, aunque podría ser un error tipográfico.

${ }_{24}$ Véanse las lecturas y variantes en el aparto crítico ofrecido en $I H C$ 84. Ponz (loc. cit.), por su parte, con una distribución de líneas distintas, ofrece annos.duos.mensem.unum, como Caro. después Morales, omite que la inscripción va encabezada por un monograma con alfa y omega inserto en un círculo.

\section{San Román de Hornija (Valladolid):}

«En San Román de Hornija dos leguas de Toro en la iglesia estan estos versos en un pilar grande.

Praecursor domini Martyr Baptista Ioannes Posside constructam in aeterno munere sedem Quam deuotus ego rex Recesuindus amator nominis ipse tui propio de Iure dicaui.

Tertio post decimum regni comes inclytus anno sexcentum decies Era nonagesima nouem.»

Evidentemente el texto corresponde al de la famosa inscripción fundacional de San Juan de Baños (ICERV 314, IHC 143). En este caso Gómez de Castro registra la correcta distribución en líneas del texto. La lectura presenta también el desarrollo habitual de las abreviaturas y la regularización de ciertas grafías, como en los casos anteriores, así Baptista por Babtista, aeterno por eterno, nouem por nobem; también escribe la grafía Ioannes frente a Iohannes que mantiene la inscripción y varía igualmente el nombre del rey ofreciendo Recesuindus por Reccesuinthus y transcribe erróneamente propio por proprio.

La variante más significativa, con todo, es la forma tertio por tertii; esta corrección fue la propuesta por Ambrosio de Morales y después seguida mayoritariamente por los diferentes editores; la expresión del reinado y la forma de datación han llevado a variadas y conocidas interpretaciones ${ }^{25}$, algunas más acertadas y otras menos, aceptándose que la lectura del año arrojaba la cifra de 661. Pero creemos que el estudio de Juan Gil (1978) sobre la fórmula de datación ha fijado de forma definitiva la misma en el 652. El trabajo de J. Gil, a pesar de ser citado, no termina de incorporarse definitivamente a la «literatura» erudita sobre la inscripción; aún se siguen barajando como posibles las dos fechas aducidas para la misma, la tradicional del 661 y la propuesta por $\mathrm{J}$. Gil del 652, fecha a la que ya se había aproximado Fita ${ }^{26}$. La argumentación de aquél resulta impeca-

25 Véase una exposición de las mismas en Gil 1978: 87-92.

26 Así Caballero y Feijoo 1998. En cambio sí la proponen y como parte del hilo argumental de su exposición Barroso y Morín de Pablos 1996, con un argumento similar al que esgrimimos aquí, si bien estos autores para reforzar su estudio sobre los canecillos que sujetan la inscripción como parte de un programa iconográfico sobre el tema del bautismo y defendiendo la cronología tradicional de época visigoda de la iglesia. 
ble ${ }^{27}$ y aclara satisfactoriamente el sintagma un tanto insólito utilizado en la expresión: tertii post dec(imu)m regni comes inclitus anno / sexcentum decies - era nonagesima-nobem; entendiendo tertii regni como año tercero del reinado y encabalgando anno con el verso siguiente, siendo la fecha anno / sexcentum decies nobem, a la que se ha intercalado la mención de la era era nonagesima (con elipsis de sescentesima). Así pues hay que entender el sentido del texto, según propone este autor, como «compañero ínclito del reino en su año tercero, después del décimo», en el año seiscientos diez veces nueve -en la era (seiscientos) noventa- ${ }^{28}$

La cuestión de la fecha no es de menor importancia, dado que quedaría mejor justificada su inclusión en el códice de Azagra (Ms. 10029 de la Biblioteca Nacional), junto a versos de Eugenio de Toledo, que ocupó su silla episcopal hasta el 657 , fecha en que murió y le sucedió Ildefonso, lo que podría si no adjudicar la composición del texto al mismo Eugenio ${ }^{29}$, sí vincularla a la actividad áulica del momento (Barroso y Morín de Pablos 1996: 189-190); aunque no sea éste un argumento definitivo, puesto que la compilación poética del precioso manuscrito debió elaborarse en varias fases reunidas probablemente más por azar que por sistema (Díaz y Díaz 1983: 51 y, especialmente, Vendrell 1979: 655-705), tiene visos de ser más que probable. No debe olvidarse que entre los poemas de Eugenio de Toledo hay más de uno susceptible de convertirse en texto epigráfico, entre ellos los epitafios compuestos para Chindasvinto y Reciberga, su nuera y esposa de Recesvinto ${ }^{30}$, lo que, creemos, no deja de ser ajeno a la cuestión que tratamos y sobre lo que volveremos inmediatamente.

En cuanto a la inscripción misma de San Juan

${ }^{27}$ Remitimos a su estudio para una explicación completa y mención de paralelismos estilísticos.

28 Véase también Gil 1973: 219, sobre el recurso estilístico utilizado en la mención de la fecha.

${ }^{29}$ Los Versi Ecclesia Snci Iohannis se hallan en el fol. 69r. dentro del cuaternión XI del manuscrito, que transmite la serie de poemas denominada Appendix Eugeniana (salvo tres de ellos), dado que estos poemas fueron considerados en un tiempo de Eugenio de Toledo, cuya obra se transmite en este manuscrito. Los folios de este cuaternión son, no obstante, de la misma mano que los ocho primeros y constituyen con ellos la antología (sector A) más antigua del manuscrito, formada muy probablemente hacia el 680 en Toledo. Desde la edición de Vollmer (1905, reimpr. 1961) este appendix se considera apócrifo. Pero es indudable que los poemas debieron pertenecer al mismo ambiente áulico y al entorno del propio Eugenio. Para una minuciosa descripción del códice, véase Vendrell 1979.

${ }^{30}$ Sobre la identificación de Reciberga como esposa de Recesvinto, y no de Chindasvinto, véase la edición de los poemas de Eugenio de Vollmer 1905 [1961 reimpr.]: 251 y ahora Arbeiter - Noack Haley 1999: 258. de Baños — sea cual sea su procedencia real-, creemos que, a pesar de las tentativas de retrasar su cronología y hacerla de época posterior, puede defenderse perfectamente su autenticidad, en relación con la fecha indicada en ella, no sólo desde el punto de vista formal, sino del contenido.

Antes de entrar en la consideración de qué significado puede tener la noticia dada por Gómez de Castro sobre la presencia de la inscripción de San Juan de Baños —o de una inscripción con idéntico texto- en San Román de Hornija, conviene llamar la atención sobre una cuestión que puede plantearse como hipótesis.

¿Por qué razón recoge Gómez de Castro estas cinco inscripciones, ninguna más, de orígenes diferentes, sin conexión unas con otras, salvo las dos primeras que aparecieron juntas?

Que se justifique dentro del carácter misceláneo de sus manuscritos no explica suficientemente la presencia de esas cinco inscripciones concretas. Pensamos que una razón probable sería su evidente interés por la época visigoda, como lo muestra su estudio sobre códices relativos a concilios y la preparación de una edición de las Etimologías isidorianas, según indicamos antes; pero otra podría también ser la relativa novedad de los hallazgos. De tres de ellas sabemos con certeza que fueron encontradas en un tiempo cercano. Las dos primeras de Sevilla en el mismo año que escribe su anotación «En este año de $1565 . . . »$ y, quizá, la noticia que le mueve a recopilar esos hallazgos. La de Cabra, sabemos que se encontró hacia 1550 en el territorio de Cisimbrium y fue trasladada a Cabra. De las otras no tenemos referencia concreta, pero unas palabras de Ambrosio de Morales podrían inducir a pensar que también el hallazgo de la de Lebrija es relativamente reciente (Lib. XI, cap. 31): «De mas adelante en tiempo deste Rey Theodorico es una piedra de sepultura, que agora se ve en Lebrija, villa principal cerca de Sevilla, encima la puerta de la Iglesia ${ }^{31}$. Tal vez agora sea por simple oposición a la época de la inscripción, pero tal vez sea porque se ve desde hace poco, en los tiempos cercanos a él.

En cuanto a la inscripción de San Juan Bautista, la primera referencia a su existencia en la iglesia de Baños de Cerrato la proporciona Ambrosio de Morales en 1577. ¿Desde cuándo se conocía? ¿Fue «descubierta» en esta época, a pesar de llevar siglos allí? Pero Gómez de Castro señala en 1565 que se conserva una inscripción con el conocido texto en San Román de Hornija, en un pilar grande, sin hacer mención, en cambio, de la de Baños. ¿Recoge

\footnotetext{
31 El subrayado es nuestro.
} 
Gómez de Castro esta información sobre Hornija porque es reciente, como ocurre con las tres primeras inscripciones que cita $\mathrm{y}$, tal vez, con la cuarta? ¿Desconoce, además, la existencia de la inscripción de Baños de Cerrato? ¿Se trata de un error de localización de la inscripción, cometido por el autor?

\section{LA INSCRIPCIÓN DE SAN JUAN EN SAN RO- MÁN DE HORNIJA}

No es posible saber qué quiere decir exactamente el autor con «un pilar grande»; en principio parece que sería un elemento distinto del soporte de la inscripción de San Juan de Baños, pero también es cierto que la vaguedad de la información puede dar pie casi a cualquier conjetura.

Hay algunos hechos que deben tenerse en cuenta para valorar el posible alcance de la noticia dada por Gómez de Castro.

Debemos apuntar en primer término que la sospecha que tuvimos inicialmente al leer estos apuntes epigráficos del autor, de que se tratase simple y llanamente de un error (como hemos sugerido por medio de una pregunta en las líneas anteriores) no se ha desvanecido $\mathrm{y}$, tal vez, sea la única explicación plausible, a pesar de que es en esta mención donde únicamente se detiene a anotar dónde está situada exactamente la localidad, «dos leguas de Toro» y, al igual que es correcta la información sobre la localización de las otras inscripciones, no habría por qué dudar de ésta, si no fuera por la evidencia de la existencia de la inscripción de San Juan de Baños, cuya colocación en la iglesia es coetánea a la construcción del edificio y unitaria con él, como creemos demuestran Caballero y Feijoo (1998).

Pero si aceptásemos que la noticia de Gómez de Castro puede ser cierta, se presentaría una segunda posibilidad, que se tratase de una copia; que en San Román hubiese otra inscripción, no conservada, con el mismo texto de la de Baños de Cerrato. No sería descabellado pensar en ello, pero habría que suponer entonces que se fundaron dos iglesias por Recesvinto, una en Hornija y otra en Baños de Cerrato ${ }^{32}$ o que una (la de Hornija) fuese copia de la otra (la de Baños) y, por tanto, falsa.

El principal escollo para suponer una fundación de una iglesia dedicada a San Juan en Hornija es

32 Tal vez la importancia de un acontecimiento como la victoria sobre Froga - como supuso Fita y recoge J. Gil 1978: 92 - lo justificase, aceptando, como hacemos, la fecha del 652. Y tal vez esa importancia justificase su inclusión en la antología originaria del Códice de Azagra. que, según transmiten los textos, en esa localidad se fundó un monasterio dedicado a San Román por Chindasvinto - aunque no se conserve nada de él-, lo que hace suponer que la iglesia estaba dedicada a este santo, originario de Antioquía, ya alabado por Prudencio en su Peristephanon y cuyo culto en época visigoda puede constatarse a través de la liturgia (García Rodríguez 1966: 214-216); esto dificulta la advocación a San Juan, salvo que, como ocurre en otras ocasiones, la iglesia de San Juan fuese un baptisterio, al lado de otra iglesia principal, formando una «iglesia doble» ${ }^{33}$.

A pesar de esta dificultad en relación con la advocación a San Juan Bautista de una iglesia en (o junto a) San Román de Hornija, no debemos olvidar la existencia de una inscripción que mencionaba una deposición de reliquias de diversos santos, datable hacia el siglo $\mathrm{x}$, hoy casi perdida por haberse reutilizado como pila de agua bendita (Arbeiter-Noack Haley 1999: 259) y que, según transmite Ambrosio de Morales, mencionaba, además de a San Román y otros santos, a San Juan Bautista:

\section{In nomine $D($ omi $)$ ni \\ Salvatoris mundi \\ Hic sunt reliquie \\ $S($ an $) c(t) i$ Romani monachi \\ $S($ an $) c(t) i$ Martini ep(iscop)i $S($ an $) c(t) e$ \\ Marine virg(ini)s S(an)c(t)i Petri Ap(osto)li \\ $S($ an $) c(t) i$ Ioannis $B(a) p(t i s)$ te $S($ an $) c(t) i$ Aciscli \\ et aliorum numero $s(a n) c(t) o r(m)$}

El casi absoluto vacío arqueológico que existe en torno a un posible origen visigodo de San Román de Hornija, dado que los restos conservados pueden remontarse a una iglesia mozárabe fechable hacia el siglo $\mathrm{x}$, afecta no sólo a la presencia de una inscripción como ésta en ese lugar, sino a las noticias dadas por los textos - en concreto la continuatio de la Historia Gothorum que afirma: Cindasvinthus... extra Toletum pace obiit, in monasterioque sancti Romani de Hornisga secus fluvium Dorii, quod ipse a fundamento aedificavit, intus ecclesiam ipsam in cornuto per quatuor partes monumento magno sepultus fuit- $\mathrm{y}$, por tanto, en la misma medida, a la fiabilidad de una y otros ${ }^{34}$.

Ahora bien, el hecho de que apenas se conserven restos arqueológicos hoy por hoy adscribibles a épo-

\footnotetext{
${ }^{33}$ Hecho nada infrecuente, por otra parte, y constatable, por ejemplo, en las conocidas iglesias de Nativola (Granada) y en diversos lugares, cf. sobre esto $H E p$ 6, 1996, ${ }^{\circ} 587$ y, sobre todo, el volumen monográfico de Antiquité Tardive 4 1996.

${ }^{34}$ Tomamos el texto de Gómez Moreno 1919 [1998]:
} 
ca visigoda ${ }^{35}$ no quiere decir que no hubiese existido una fundación de un monasterio por parte de Chindasvinto en Hornija y que, como quiere la tradición, fuese pensado para ser enterrado allí él y también lo fuese después Reciberga, la esposa de Recesvinto ${ }^{36}$.

Es precisamente la vinculación tradicional antigua de Hornija con Chindasvinto lo que hace tan sugerente la noticia de Gómez de Castro. Recordemos lo indicado líneas antes, que fue Eugenio de Toledo quien, entre otros epitafios, compuso los de Chindasvinto y Reciberga y recordemos que la inscripción de San Juan de Baños es un poema que, sin duda, debió componerse en el entorno y época de Eugenio de Toledo y que, como tal, pasó a la antología más antigua del Códice de Azagra, compilada en Toledo alrededor del 680 . Puede pensarse, entonces, que Recesvinto mandó construir una iglesia con advocación a San Juan Bautista (¿un baptisterio?), junto al monasterio que había fundado su padre, siendo corregente con él. Creemos que la vinculación de unos datos y otros es algo más que casual.

Los mencionados autores, Arbeiter y Noack Haley (1999: 258-261), en su reciente estudio sobre las iglesias altomedievales hispanas, consideran que los testimonios dados por Ambrosio de Morales en cuanto a que él vio algunos restos de la iglesia de época visigoda en Hornija pueden ser creíbles, a pesar de que ya no quede nada de ella. Y son precisamente los testimonios de éste los que procede recordar aquí, porque, aunque sea por casualidad, conectan ambas iglesias entre sí.

Morales recoge la conocida noticia del enterramiento de Chindasvinto en Hornija y describe su ubicación, a lo que añade: «Yo ví la iglesia antigua de obra gótica con su crucero de quatro brazos, como lo describe San Ildefonso quando habla de su fundación. Mas por haber después querido ensanchar la capilla mayor, se ha perdido la forma de la fábrica antigua y sólo quedan muchas de las ricas colunas de diversos generos y colores de marmoles que había en todo el edificio. Allí está la sepultura del rey en una capilla, en una gran tumba de marmol blanco, su cubierta de lo mismo. Letras no hay en la capilla ni en el túmulo. En el libro gótico anti-

35 Gómez Moreno 1919 [1998]: 185-192 y Arbeiter Noack Haley 1999: 258-261, con bibliografía anterior. No obstante, según estos autores algunos capiteles y otros elementos pueden pertenecer a esta época.

${ }^{36}$ Entre los restos arqueológicos expuestos en el interior de la iglesia actual de la localidad hay unos huesos humanos atribuidos a estos personajes reales. Arbeiter - Noack Haley 1999: 258 conceden fiabilidad a que estos restos, dado el análisis que se ha realizado sobre ellos, puedan pertenecer efectivamente a ellos. guo del Secretario Miguel Ruiz de Azagra, de quien dixe en su lugar, están entre otros epigramas los epitafios deste Rey y de la Reina, su mujer. Y no hay duda sino que el autor dellos es el arzobispo Eugenio, pues están entre sus obras».

De este testimonio, por lo demás bien conocido, cabe deducir que la iglesia ha sufrido en esos años una profunda reforma - después de otras diversas ya desde lo que puede suponerse la gran transformación en torno al siglo $\mathrm{x}-$; una reforma que ha desfigurado la «antigua fábrica» de la iglesia primitiva (aunque no sepamos si lo que vio Morales fue la construcción mozárabe o si había algún resto de época visigoda como indica).

Ante la afirmación de Morales sería lícito conjeturar que en esa reforma pudo hallarse la inscripción de San Juan Bautista grabada «en un pilar grande» de que habla Gómez de Castro y que, sin duda, cuando visitó la iglesia Morales ya no se hallaba allí.

No es más que una conjetura pero quizá no imposible. A este propósito la comparación que establece Ambrosio de Morales entre ambos lugares hace tentadora cualquier hipótesis de este tipo; al describir Baños afirma (Lib. XII, cap. 36): «Allí (sc. Baños) fundó el Rey Recesvindo una Iglesia, con advocación de San Juan Bautista, el año de nuestro Redentor seiscientos y sesenta y uno, que fue el treceno de su Reyno, como él lo dice en la piedra de la dedicación, que está dentro de la Iglesia, la qual dura entera hasta agora con muestra de su antigüedad y forma y fábrica de Godos. Tiene muy ricos marmoles y jaspes de diversas colores, como los godos usaban y en la Iglesia del enterramiento de su padre (sc. San Román de Hornija), como hemos dicho, parece. Y ya atrás dixe como estos dos Reyes, padre e hijo, creo cierto eran naturales de tierra de campos y el edificar este Rey ( $s c$. Recesvinto) allí esta iglesia (sc. San Juan de Baños) lo confirma» ${ }^{37}$.

Cabría una tercera posibilidad, pero hoy por hoy creemos que errática, dado que la inscripción de San Juan de Baños está instalada en la iglesia desde la construcción de la misma, como se ha indicado.

Del apéndice documental existente sobre San Juan de Baños, que ofrecen Caballero y Feijoo 1998: 237-238, se deduce que ha habido diversas obras y remodelaciones, tal vez tantas que el resultado hoy visible de la paradigmática iglesia sea mínimamente parecido a su forma original, fuese de la época que fuese. Entre esas remodelaciones cabe destacar que hubo una precisamente en 1565 -fe-

37 El subrayado es nuestro. 
cha de la nota de Gómez de Castro-que debió ser importante, según lo que de la noticia conservada cabe deducir: «que la socazen de por fuera y aderecen en todo lo que fuere necesidad e hagan sacar un lienzo de la parte del cierzo que se haga alto media vara a tres cuartas para que corra el agua afuera e no mojare a la iglesia e por la parte del aire al abrigo frio de la iglesia».

Por otra parte, parece evidente que Ambrosio de Morales, a juzgar por sus afirmaciones, visitó personalmente tanto Hornija como Baños de Cerrato, aunque no sabemos en qué fecha, dado que estas inscripciones no quedan recogidas en la relación del viaje que hizo en 1572 a los reinos de León y Galicia y Asturias, por orden de Felipe II, precisamente para recopilar noticias de inscripciones, sepulcros reales y manuscritos ${ }^{38}$, y resulta extraño que no incorporase a esa relación las visitas a ambos pueblos y la mención de lo que vio en ellos; así habría que suponer que los visitó con posterioridad, y antes de 1577, fecha de la Crónica, donde ya aparecen citados. Del testimonio de Morales sobre Hornija, antes comentado, se deduce también que la iglesia de San Román fue reformada por esos años.

¿Las reformas prácticamente coetáneas de Hornija y Baños pudieron dar como resultado el «traslado» de la inscripción? La respuesta, en este caso, parece que debe ser negativa, pues la evidencia arqueológica de San Juan de Baños habla en contra de ello.

\section{¿AMBROSIO DE MORALES VERSUS GÓMEZ DE CASTRO?}

La comparación entre la nota de Gómez de Castro y los testimonios de Morales apunta a la posibilidad de un contacto entre ambos autores - habida cuenta de su amistad y correspondencia mutua-, o una fuente de información común, en relación con las cinco inscripciones concretas que recoge el primero.

38 La relación de este viaje se conserva en los mss. 2063 y 7974 de la Biblioteca Nacional y fue posteriormente editada por H. Flórez en 1765: Viage de Ambrosio de Morales por orden del rey D. Phelippe II, a los reynos de León, y Galicia, y principado de Asturias para reconocer las reliquias de santos, sepulcros reales y libros manuscritos de las cathedrales y monesterios. No parece, en cambio, que Gómez de Castro viera personalmente ninguna de las inscripciones, a juzgar por su trayectoria biográfica, pero ignoramos cómo pudo conocer la información, por otra parte rápidamente adquirida, al menos en relación con los hallazgos más recientemente producidos de Sevilla. Podría pensarse en el propio Morales, pero todo parece indicar que la obtención de datos de éste es posterior a la de Gómez de Castro.
Hay datos coincidentes -incluso omisionesque permiten suponerlo, especialmente la variante tertio en la fecha de la inscripción de Baños, cuando en ella se lee tertii; la anotación marginal de Gómez de Castro del reinado de los reyes coetáneos a las fechas de las inscripciones de Sevilla, teniendo en cuenta que Morales las presenta en los capítulos relativos a la historia de Teudis y Atanagildo respectivamente ${ }^{39}$; incluso la omisión en ambos del encabezamiento de monograma, con alfa y omega, inserto en un círculo de la inscripción de Lebrija.

Pero también hay datos divergentes bastante significativos. Sobre las inscripciones de Sevilla, ambos autores comentan que en cada uno de los dos sepulcros apareció un vaso (o redoma) de vidrio que contenía licor, según Gómez de Castro en bastante buen estado, según Morales, que advierte que «los vio», el licor estaba completamente consumido. Resulta sugerente pensar que Morales está corrigiendo tácitamente a Gómez de Castro (o a quien o quienes hayan facilitado esa información), apoyándose en que ha visto los hallazgos. Este dato sólo no sería suficiente, pero si lo unimos a la afirmación hecha sobre San Román de que él ha visto la iglesia y que «letras no hay en la capilla ni en el túmulo», da la impresión de que está, nuevamente de forma tácita, contradiciendo la información de Gómez de Castro (o, insistimos, posibles informaciones que circulasen sobre la existencia de una inscripción en San Román de Hornija).

Es posible que esta lectura «entre líneas» sea exclusiva de quienes firmamos este trabajo, pero quizá haya algo de ello en los comentarios de Morales. En todo caso resulta chocante que ambos autores se silencien mutuamente y resulta también sorprendente que las noticias dadas por Gómez de Castro hayan quedado ignoradas desde entonces.

Concluimos con nuestro propósito al iniciar este trabajo: ofrecer una información inédita sobre unos desconocidos apuntes epigráficos de Gómez de Castro ${ }^{40}$, que consideramos tienen un interés intrínseco, y presentar esa desconcertante noticia de la presencia de una inscripción en San Román de Hornija con el texto fundacional conocido de la iglesia de San Juan en Baños de Cerrato, para que la sometan a valoración quienes conocen y están cualificados para juzgar tan famoso monumento arquitectónico.

39 Recuérdese al respecto el error de intercambio de las notas de Gómez de Castro, apuntado en nota 14.

40 Sólo mencionados en el conjunto de la descripción del manuscrito de Alvar 1980. 


\section{BIBLIOGRAFÍA}

Alonso, D. 1970: Dos españoles del siglo de Oro, Madrid.

Alvar Ezquerra, A. 1980: Acercamiento a la poesía de Álvar Gómez de Castro (Ensayo de una biografía y edición de su poesía latina), 2 vols. Madrid.

Alvar Ezquerra, A. 1982: Álvar Gómez de Castro, humanista, Revista de Filología Española 62, 193-210.

Alvar EzQuerra, A. 1985: Álvar Gómez de Castro y la historiografía latina del siglo xvi: la Vida de Cisneros, en M. Revuelta y C. Morón (eds.), $E l$ erasmismo en España, Santander, 247-264.

Antiquité Tardive 4, $1996=$ N. Duval - J.P. Caillet (Eds.), Les églises doubles et les familles d'églises (Table Ronde organisée à Grenoble en juin 1994), 19-234.

Arbeiter, A. - NoACK Haley, S., 1999: Christliche Denkmäler des frühen Mittelalters vom 8. bis ins 11. Jahrhundert, Hispania Antiqua, Mainz am Rhein.

Barroso Cabrera, R. - Morín de Pablos, J. 1996: Los canecillos de San Juan de Baños. Una iconografía bautismal vinculada a la inscripción de Recesvinto, Madrider Mitteilungen 37, 187 204.

Caballero Zoreda, L., 1994-5: Un canal de transmisión de lo clásico en la alta Edad Media española. Arquitectura y escultura de influjo omeya en la Península Ibérica entre mediados del siglo VIII e inicios del siglo X, Al-Qantara 15-6, 32148 y $107-24$.

Caballero Zoreda, L. - Feijoo Martínez, S., 1998: La iglesia altomedieval de San Juan Bautista en Baños de Cerrato (Palencia), Archivo Español de Arqueología 71, 181-242.

Caballero Zoreda, L. - SÁez lara, F., 1999: la Iglesia Mozárabe de Santa Lucía del Trampal, Alcuéscar (Cáceres), Mérida.

CIL II ${ }^{2} / 5$ = Stylow, A.U. - Atencia Páez, R.- González Fernández, J. - González Román, C. - Pastor Muñoz, M. - Rodríguez Oliva, P. (Eds.) 1998: Corpus Inscriptionum Latinarum II: Inscriptiones Hispanae Latinae, ed. altera, pars. V. Conventus Astigitanus, Berlin-New York.

Díaz y DíAz, M.C., 1983: Códices visigóticos en la monarquía leonesa, León.

FLóREZ, H., 1765 [reimpr. facsimil 1977]: Viage de Ambrosio de Morales por orden del rey D. Phelippe II, a los reynos de León, y Galicia, y principado de Asturias para reconocer las reliquias de santos, sepulcros reales y libros manuscritos de las cathedrales y monesterios. Editorial Antonio Marín, Madrid, 1765 (reimpr. Oviedo 1977).

Fontán, A., 1972: El latín de los humanistas, Estudios Clásicos XVI, 183-203.

García Rodríguez, C., 1966: El culto de los santos en la España romana y visigoda, Madrid.

Gigas, E., 1909: Lettres inédites de quelques savant espagnols du XVIè siècle, Revue Hispanique 20, 429-450.

GIL FernándeZ, J., 1971: Sobre las inscripciones 110 y 111 del 'Corpus' de Vives, Habis 2, 283284.

Gil Fernández, J., 1973: Para la edición de los textos visigodos y mozárabes, Habis 4, 189-234.

GIL FernándeZ, J., 1978: Epigraphica III, Cuadernos de Filología Clásica 14, 83-120.

Gil Fernández, L., 1997: Panorama social del Humanismo español (1500-1800), (2 ${ }^{\mathrm{a}}$ edic.), Madrid.

Gómez Moreno, M., 1919 [reimpr. 1997]: Iglesias mozárabes, Madid. Estudio preliminar de I. Bango Torviso.

Grabar, O., 1954: The Painting of the Six Kings at Qusayr Amrah, Ars Orientalis 1, 185-187.

GrABAR, O., 1981: La formación del arte islámico, Madrid.

Grabar, O. y A., 1965: L'essor des Arts inspirés par les cours princières à la fin du premier millénaire: princes musulmans et princes chrétiens, Settimane di Studio del Centro Italiano di Studi sull'Alto Medioevo. L'Occidente e l'Islam nell'Alto Medioevo, Spoleto, II, 845-901.

$H E p=$ Hispania Epigraphica 1996, 6. Revista de la Universidad Complutense.

ICERV = Vives, J. 1969: Inscripciones cristianas de la España romana y visigoda, Barcelona, $2^{\mathrm{a}}$ edic.

$I H C=$ Hübner, E. 1871 [1975 reimpr.]: Inscriptiones Hispanae Christianae, Hildesheim-New York.

LóPez DE TORo, J., 1958: Perfiles humanos de Cisneros (Trayectoria de una biografía), Madrid.

Morales, A. de, 1574-1586 y [1791 reed.], Coronica General de España que continuaba Ambrosio de Morales, coronista del rey nuestro señor D. Felipe II, Alcalá de Henares y [Madrid].

Oroz Reta, J., 1984: Álvar Gómez de Castro. De las hazañas de Francisco Jiménez de Cisneros. Edición, traducción y notas por..., Madrid.

Ponz, A., 1787 y 1794 : Viage de España, 2a edición, Madrid, vols. XI y XVIII.

Recio Veganzones, A., 1979: Baetica paleocristiana y visigoda: la antigua Nebrissa, hoy Lebrija (Sevilla), Rivista di Archeologia cristiana 55, 47-88.

SÁnchez Albornoz, C., 1980: La España cristiana de los siglos VIII al XI. El reino asturleonés $(722$ 
a 1037). Historia de España Menéndez Pidal, Madrid, Tomo VII.

Sánchez Cantón, F.J., 1919: El Arte de Trovar de Don Enrique de Villena, Revista de Filología Española $6,158-180$.

Vendrell Peñaranda, M., 1979: Estudio del códice de Azagra, Biblioteca Nacional de Madrid, ms. 10029, Revista de Archivos, Bibliotecas y $\mathrm{Mu}$ seos $82,655-705$

Vollmer, F. (Ed.), 1905 [1961 reimpr.]: Eugenius Toletanus, Carmina. MGH, auct. antiq. XIV, Berlin. 